\title{
Percutaneous Trucut lung biopsy in the diagnosis of localised pulmonary lesions
}

\author{
BDW HARRISON, RS THORPE, PG KITCHENER, BG McCANN, JR PILLING
}

From the Departments of Respiratory Medicine, Radiology, and Histopathology, West Norwich and Norfolk and Norwich Hospitals, Norwich

ABSTRACT In a prospective evaluation of percutaneous Trucut needle biopsy for localised intrathoracic lesions in 89 patients histological specimens were obtained in 81 . Malignancy was diagnosed in 66 cases. Subsequently definitive histological reports were available in 18 of these patients with complete concordance of malignant cell type. Sixteen patients had non-malignant histological appearances, which were later confirmed objectively in six. In three patients there was no follow up information, but in the remainder the clinical course was entirely consistent with the histological appearances of the biopsy specimens. Adequate specimens were obtained from only two of the five lesions less than $2 \mathrm{~cm}$ in diameter. Lesions deeper than $8 \mathrm{~cm}$ from the site of biopsy were associated with significantly more haemorrhagic complications than more superficial lesions. Comparison with other series indicates that Trucut needle biopsy which produces histological specimens has greater diagnostic accuracy than cytological techniques for both malignant and non-malignant localised lesions. It is concluded that this technique has a definite place in the investigation of this common problem in carefully selected patients provided that strict attention is paid to the details of the technique.

Leyden' is credited with the first diagnostic pulmonary needle aspiration in a patient with pneumonia, but Menetrier ${ }^{2}$ probably performed the first cutting needle biopsy for histological diagnosis. Since 1959 several groups have reported on the diagnostic use of percutaneous cutting needle biopsy in the diagnosis of lung disease. ${ }^{3-12}$ All but three of these studies $^{346}$ included patients with diffuse lung disease as well as patients with localised lesions, and most if not all were retrospective surveys. Recent reviews have concluded that cutting needles should no longer be used because the incidence of complications (such as haemorrhage, pneumothorax, and air embolism) and mortality rate are unacceptably high. ${ }^{1314}$ Review of the published series, however, suggests that most of the serious complications occurred in patients with diffuse or fibrotic lung disease-a point emphasised by Aronvitch et al, ${ }^{\circ}$ Youmans et al, ${ }^{10}$ and Zavala and Bedell. ${ }^{11}$ Furthermore, in the earlier series (where complication rates

Address for reprint requests: Dr B D W Harrison, Department of Respiratory Medicine, West Norwich Hospital, Norwich NR2 3TU.

Accepted 7 March 1984 were high) the biopsies were performed without $x$ ray screening control.

Recently techniques of lung "biopsy" which produce cytological specimens have gained popularity. These include aspiration and use of the Nordenstrom screw or one of its variants. The advantage claimed for this technique is that it is safer, but the disadvantages include the requirement of an expert cytopathologist and the fact that non-malignant and some malignant lesions are difficult to categorise.

For these reasons we have conducted a prospective study of the value of percutaneous biopsy with a Trucut needle in patients with localised intrathoracic lesions. Our results indicate that this technique is not as dangerous as recent reviews have suggested. The complication rate is similar to the rates reported for aspiration and Nordenstrom screw techniques and the diagnostic yield is very high.

\section{Methods}

THE PATIENTS

From June 1978 to July 198389 patients, aged 23-81 (mean 62) years, had percutaneous lung biopsy. Details of their age and sex; site; size and depth of lesion assessed from the chest radiograph; 
the presumed diagnosis; results of spirometry; presence or absence of radiographic evidence of emphysema; histological diagnosis; and complications were recorded on a standard form. Most had a suspected lung tumour. Before biopsy, all cases were discussed by a radiologist, a thoracic physician, and usually a thoracic surgeon. Patients had posteroanterior and lateral chest radiographs and in most cases anteroposterior or lateral tomograms to localise the lesion. Before biopsy two patients had pulmonary angiography to exclude aneurysm and arteriovenous malformation, one aortography to exclude an aneurysm, and one ultrasound examination to ensure that the "mass" was not a Bochdalek hernia. Spirometry was performed with a Vitalograph dry spirometer and all patients had a clotting screen and were blood grouped. Thirty two patients had had bronchoscopy with negative results.

Absolute contraindications to the procedure included any blood clotting abnormality, inability to withstand a pneumothorax, pulmonary hypertension or an uncooperative patient. 5781115

\section{TECHNIQUE OF BIOPSY}

The patients had their biopsies in the early afternoon after a normal breakfast but no lunch. Most received no premedication. In the radiology theatre, the patient was usually positioned by means of single plane screening so that the vertical distance between the chest wall and the "mass" was the shortest possible compatible with a view of the lesion. The patient was then made comfortable in this position and $0.5 \%$ lignocaine was infiltrated into the skin and underlying tissues. Whenever the operator felt the anaesthetic needle approaching the pleura he asked the patient to stop breathing to avoid a pleural tear. The distance between the skin surface and the proximal edge of the mass was measured from the radiographs and this distance was marked on the Trucut needle with plastic Spencer Wells forceps or with a finger. The Trucut needle was introduced through a small scapel incision and advanced into the lung in a vertical direction to the appropriate depth. During this time the patient was once again asked not to breathe. The position of the needle was then checked on the image intensifier screen. In difficult cases the needle was actually introduced into the lesion under direct vision. The mass could often be felt as a solid resistance when the tip of the needle entered it. Confirmation that the tip of the needle lay in the mass was obtained by parallax during respiration and by rotating the patient gently with the needle in place. The inner stylet of the Trucut needle was then advanced fully and the position usually checked again. The cutting sheath of the needle was advanced, the biopsy specimen obtained, and the needle removed from the patient. Whenever the needle was being manipulated the patient was asked not to breathe. In most patients two or three biopsies, or biopsy attempts, were carried out. No further biopsies were performed if there was the slightest degree of haemoptysis or if a pneumothorax developed. We found it helpful for the biopsy to be performed jointly by a physician and a radiologist, although some were performed single handed by either specialist. After the biopsy a chest radiograph was taken in expiration and this was repeated the following morning, and the patient was discharged from hospital if there was no pneumothorax. A thoracic surgeon was operating in the same hospital whenever we performed Trucut needle biopsies.

\section{Results}

The $\mathrm{FEV}_{1}$ values of the 89 patients ranged from 0.55 to 4.3 litres, and seven patients had an $\mathrm{FEV}_{1}$ of one litre or less. The histological appearances of the biopsy specimens were of malignant disease in 66 of

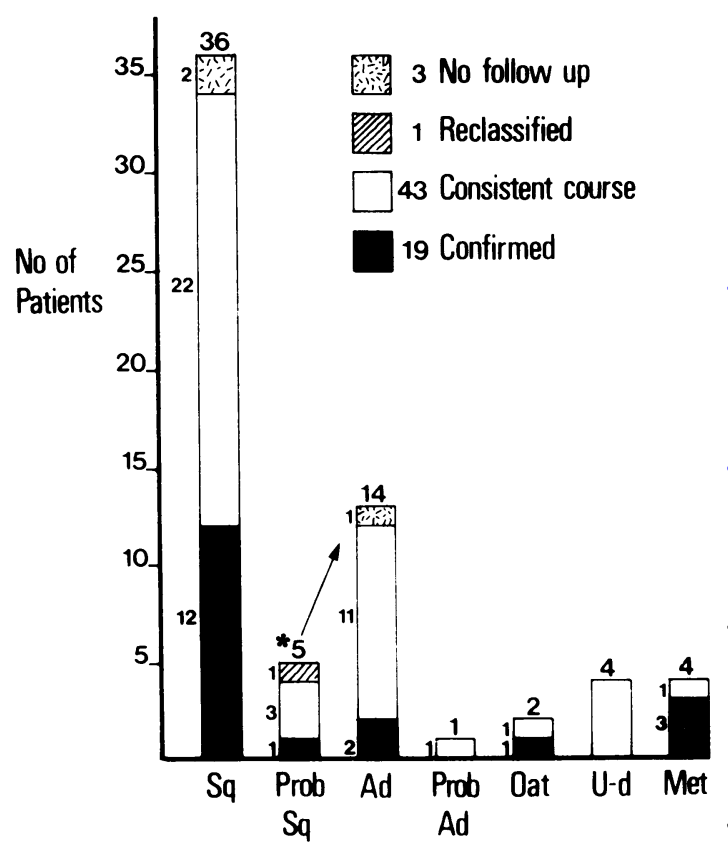

Fig 1 Distribution of histological diagnoses in 66 patients with histological malignancy. $S q$-squamous cell carcinoma; Prob. Sq-carcinoma probably squamous; Ad-adenocarcinoma; Prob Ad-carcinoma probably adenocarcinoma; Oat-oat cell carcinoma; U-d-undifferentiated carcinoma; Met-secondary carcinoma (primary tumours: I adenocarcinoma of colon, I seminoma, l osteosarcoma, 1 hypernephroma). 
the 89 cases and of non-malignant disease in 16; in seven cases either no tissue or unhelpful tissue was obtained. A positive histological diagnosis was obtained in $92 \%$ of cases.

Figure 1 shows an analysis of the 66 malignant lesions. The commonest histological diagnosis was squamous cell carcinoma. In the malignant group confirmation of the histological diagnosis was obtained in 18 cases at thoracotomy, mediastinoscopy, or necropsy. One diagnosis of squamous cell carcinoma was supported by the later finding of malignant squames on cytological examination of sputum. In one man the material obtained was insufficient for histological examination but cytological examination of the Trucut needle specimen suggested a probably squamous carcinoma. At thoracotomy the tumour was found to be an adenocarcinoma. Forty three of the remaining 46 patients showed clinical deterioration, development of metastatic disease, and a response to radiotherapy that were consistent with the diagnosis of carcinoma.

\section{Tabel 1 Diagnosis in 16 patients with benign histological} appearances

Organising pneumonia ( 4 cases)
Pulmonary infarct ( 2 cases)
Chronic inflammation-confirmed at necropsy 1 year later: no
pathological lesion
Empyema-aspirated and cured
Tuberculosis-confirmed sputum culture
Sarcoidosis
Benign fibrosis
Fibroma of diaphragm $\}$ confirmed at thoracotomy
Pleural fibroma
Chondromatous hamartoma
Wegener's granulomatosis-confirmed by nasal biopsy and
necropsy
Lymphomatoid granulomatosis

The diagnoses in the 16 patients with nonmalignant histological appearances are listed in table 1. There was objective support for the diagnosis of a benign lesion in six cases (table 1) and the subsequent clinical course was "benign" in all 16 during a follow up period ranging from eight months to four years.

Clinical details and outcome in the four patients with unhelpful histology and in the three from whom no tissue was obtained are given in table 2 .

Figure 2 shows the distribution of the sizes of the lesions as seen on the chest radiograph. Eighty one $(89 \%)$ were $2-10 \mathrm{~cm}$ in maximum diameter. The biopsy produced diagnostic material from only two of the five lesions that were less than $2 \mathrm{~cm}$ in diameter.

The distribution of the depths of the lesions from the biopsy site is shown in figure 3 . In $73 \%$ of cases the lesion lay $3-8 \mathrm{~cm}$ from the body surface. Nineteen patients had lesions at a depth of $9 \mathrm{~cm}$ or more. The biopsy specimen was diagnostic in 17 of these but eight developed a pneumothorax (requiring an intercostal tube in one) and eight had haemoptysis, which was large or severe in four.

Twenty three patients developed a pneumothorax but only four required intercostal tube drainage. Demonstrable haemorrhage occurred in 17 patients. In 11 this was a small amount of blood spitting (including blood streaking of the sputum) or a small increase in the size of the mass on the chest radiograph. In five patients $50-150 \mathrm{ml}$ of blood were expectorated. A further patient developed a large presumed haemothorax after the biopsy. She refused further diagnostic procedures and was the only patient who required a blood transfusion. The difference between the frequency of large haemorrhages when the lesion was $9 \mathrm{~cm}$ deep or more and

Table 2 Details of the seven patients in whom the biopsy was non-contributory

\begin{tabular}{|c|c|c|c|c|c|}
\hline $\begin{array}{l}\text { Patient } \\
\text { Vo }\end{array}$ & $\begin{array}{l}\text { Size of } \\
\text { mass }(\mathrm{cm})\end{array}$ & $\begin{array}{l}\text { Depth of } \\
\text { mass }(\mathrm{cm})\end{array}$ & $\begin{array}{l}\text { Tissue obtained } \\
\text { from mass }\end{array}$ & Histological report & Follow up \\
\hline 14 & 6 & 10 & Yes & $\begin{array}{l}\text { Severe interstitial pulmonary fibrosis } \\
\text { with arterial narrowing but no } \\
\text { evidence of vasculitis or neoplasm; one } \\
\text { focus of recent necrosis }\end{array}$ & $\begin{array}{l}\text { Developed cerebellar syndrome and computed } \\
\text { tomography showed widespread cerebral and } \\
\text { cerebellar metastases; died } 4 \mathrm{~m} \text { after biopsy }\end{array}$ \\
\hline 23 & $1 \cdot 5$ & 9 & Yes & $\begin{array}{l}\text { No definite diagnosis-possibilities } \\
\text { include degenerate tumour, lung infarct, } \\
\text { or (less likely) tuberculosis }\end{array}$ & $\begin{array}{l}\text { Refused further investigations; alive and active } \\
18 \mathrm{~m} \text { later }\end{array}$ \\
\hline 43 & 2 & $?$ & Yes & $\begin{array}{l}\text { Blood clot and fragments of fibrotic } \\
\text { pleura }\end{array}$ & $\begin{array}{l}\text { Underlying chronic lymphatic leukaemia, and } \\
\text { it was decided to investigate mass on chest } \\
\text { radiograph no further; alive } 2 \text { y later }\end{array}$ \\
\hline 56 & $1 \cdot 5$ & 8 & No & & $\begin{array}{l}\text { Thoracotomy and resection advised; patient } \\
\text { refused and sought advice at another hospital; } \\
\text { lost to follow up }\end{array}$ \\
\hline 57 & 3 & 5 & No & & $\begin{array}{l}\text { Thoracotomy was to be advised but evidence of } \\
\text { widespread metastases developed within a } \\
\text { month; died } 2 \text { m later }\end{array}$ \\
\hline 62 & $1 \cdot 5$ & 5 & No & & $\begin{array}{l}\text { Thoracotomy accepted; left lower lobectomy } \\
\text { for carcinoma performed }\end{array}$ \\
\hline 79 & 10 & 6 & Yes & $\begin{array}{l}\text { Non-specific interstitial fibrosis; no } \\
\text { evidence of neoplasm }\end{array}$ & Thoracotomy accepted; empyema drained \\
\hline
\end{tabular}




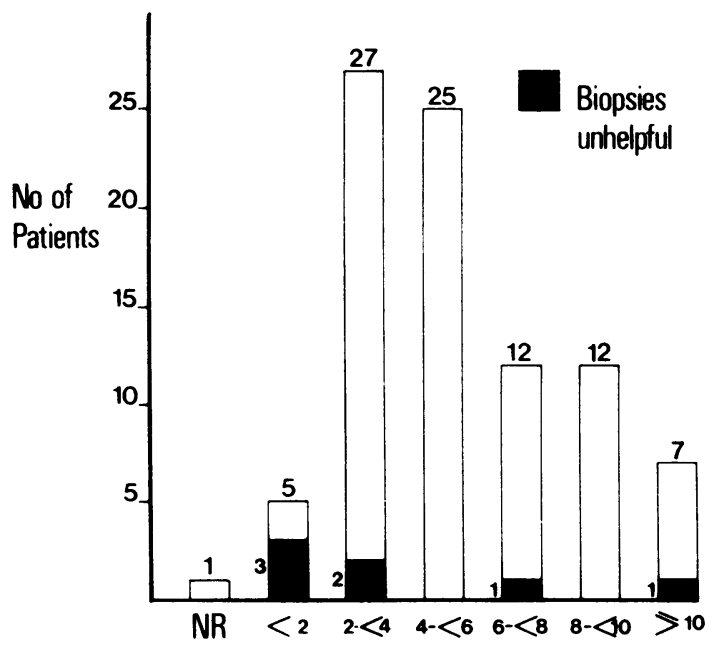

Size in $\mathrm{cm}$

Fig 2 Distribution of the size of the lesions on the chest radiographs of the 89 patients. NR-not recorded.

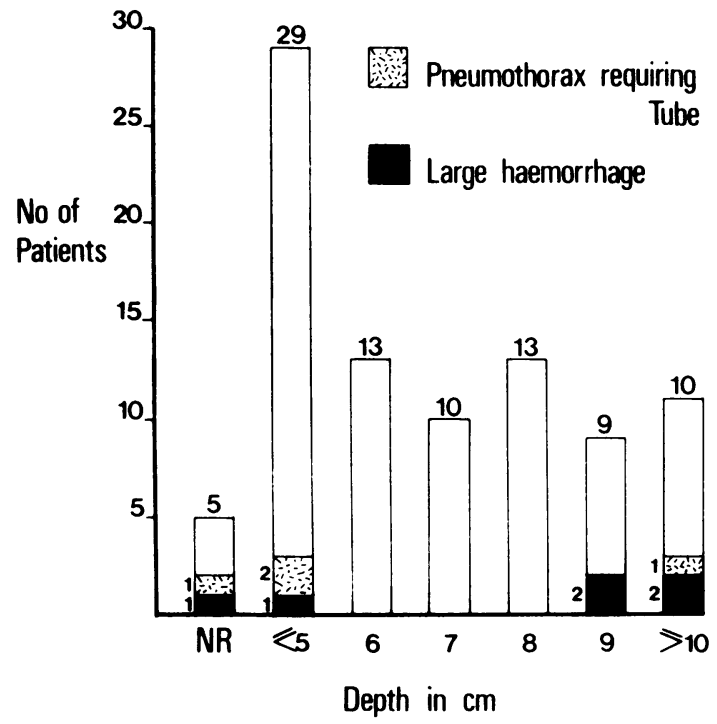

Fig 3 Distribution of the depth of the lesions from the skin surface measured from the chest radiographs of the 89 patients. NR-not recorded.

when it was more superficial was significant $\left(\chi^{2}=\right.$ $5.24 ; p<0.05)$. The incidence of pneumothoraces (including those requiring an intercostal tube) was not significantly related to the depth of the lesion or to the FEV .

Two patients subsequently developed secondary deposits at the site of the biopsy wound. In one an adenocarcinoma had been successfully removed at
Table 3 Indications and contraindications for percutaneous Trucut biopsy of localised intrathoracic lesions

Indications

1 Where bronchoscopy with negative results has been performed or is anticipated

2 Where surgery is not contemplated but a firm diagnosis is required for management

3 Where surgery is being considered but associated problems make the decision difficult

4 Where a diagnosis of a non-malignant condition is expected

5 Where there are multiple lesions

Contraindications

1 Inability to withstand a pneumothorax

2 Pulmonary hypertension

3 Bleeding or clotting disorder

4 Total inability to cooperate

5 Lesion less than $2 \mathrm{~cm}$ in diameter

6 Lesion more than $8 \mathrm{~cm}$ from skin surface

lobectomy. Two and a half years later, when the secondary deposit on the skin appeared, there was no other evidence of recurrence or metastases. The deposit was exised and two years later he was well with no evidence of further recurrence or matastases. In the other patient a squamous cell carcinoma had been considered inoperable and treated with radiotherapy. The metastasis that appeared in the needle track six months later responded to further radiotherapy. Five months later he moved to Scotland.

There were no air emboli and no fatal complications in this series.

\section{Discussion}

Comparison of earlier series of cutting needle biopsies and of "aspiration" cytology techniques

Ten series of cutting needle biopsies have been reported since $1959,,^{3-12}$ but in none was validation of the biopsy diagnosis by subsequent necropsy, surgical, or clinical evidence mentioned. The most recent paper ${ }^{12}$ reported a questionnaire survey and included 186 patients with suspected tumours. From these reports we can draw the following conclusions. A total of 626 patients with localised lesions were submitted for biopsy. Positive diagnoses were obtained in $54-100 \%$ of patients, the overwhelming majority being of malignant disease. Pneumothoraces were reported in $0-20 \%$ of patients and intercostal tubes were required in up to $5.5 \%$. Haemoptysis was infrequently reported (in up to $7.1 \%$ of cases in the questionnaire survey ${ }^{12}$ ) and serious haemorrhage was reported only in the questionnaire survey $(0.5 \%)$. One death was reported in the questionnaire survey, but it is unclear whether this patient had diffuse or localised lung disease. All the other deaths reported in these series occurred in patients with diffuse lung disease. 
A further fatality, reported by Meyer et al ${ }^{16}$ also occurred in a patient with diffuse disease.

There have however, been two reports of death after biopsy of localised lung lesions with a VimSilverman needle. ${ }^{17}$ Both died from haemorrhage. One of the biopsies was performed without screening control and it is clear from the report that three "blind" attempts were made before the patient collapsed. There have also been reports of three patients in whom secondary deposits of tumour developed in the needle track after cutting lung biopsy. ${ }^{6} 1814$

Since 1965 there have been more reports of needle aspiration or screw techniques which produce cytological specimens. ${ }^{20-31}$ Diagnostic accuracy for malignant lesions ranged from $50 \%$ to $96 \%$. After this procedure the pneumothorax rate ranged from $7.5 \%$ to $49 \%$, intercostal tubes being required in $1.3-21 \%$ of patients; complicating haemorrhage occurred in $0-37 \%$ and major haemorrhage in 0 $2 \cdot 1 \%$, and fatal complications were reported in 0 $0.69 \%$ of patients. Three further fatalities have been reported after aspiration, ${ }^{32-34}$ all three in patients with diffuse pulmonary disease.

All reports of aspiration cytology have emphasised the importance of an expert cytopathologist and yet the concordance of aspiration cytology with definitive histology was generally poor ${ }^{35-37}$ even for squamous cell carcinoma, the commonest cell type. Most series have contained examples of patients with malignant disease who were incorrectly diagnosed as suffering from benign lesions on the basis of this technique. In four recent series the false negative rate in patients with malignant disease was $4 \%,{ }^{30} 11 \%,{ }^{35} 12 \%,{ }^{27}$ and $4-13 \%$ (depending on aspiration technique)..$^{38}$

Another major problem with aspiration techniques was the difficulty of diagnosing benign lesions accurately, even when the material aspirated was examined histologically. ${ }^{38}$ Of the non-malignant lesions sampled in this most recent series, only $40 \%$ had a benign process diagnosed. ${ }^{38}$

\section{Diagnostic accuracy and usefulness in the present series}

Our series suggests that Trucut biopsies have a definite place in the diagnosis of localised intrathoracic lesions. The overall positive diagnosis rate of $92 \%$ compares very favourably with the rates in published series of cutting and aspiration biopsies. Of the 18 patients in whom a histological diagnosis of malignant disease was made from biopsy material and on whom surgical biopsy or necropsy was later performed, none required revision of the initial histological diagnosis. None of the 16 patients with a non-malignant histological diagnosis subsequently required revision of the diagnosis. Many of this group had been referred because of suspected malignant disease and the finding of Wegener's granulomatosis, lymphomatoid granulomatosis, and empyema, for example, completely altered the patients' management and prognosis.

We failed to obtain useful material from seven patients, in three of whom the lesion was missed. Of the five patients with lesions less than $2 \mathrm{~cm}$ in diameter, we missed the lesion in two and obtained unhelpful histological material in a third. We would now not advise Trucut needle biopsy in this group-a conclusion which supports those of two earlier studies. 615

Non-contributory histological material should be regarded not as reassuring but as representing a failed investigation. Thoracotomy was subsequently advised or would have been advised in four of our patients (table 2). Development of a cerebellar syndrome in a fifth led to computed tomography, which showed evidence of widespread cerebral and cerebellar metastases. One woman refused further investigation and management was expectant in another because of her age, general condition, and underlying leukaemia.

\section{Complication rates}

The complication rates were similar to those reported for cutting needle and aspiration biopsies. Our contraindications to biopsy were based on commonsense and on published recommendations. We believe that the details of our technique were also very important in minimising complications. We collected information prospectively and the accuracy of reporting, especially of haemorrhage, is likely to be greater than in retrospective series. Believing that pneumothoraces are often caused by the local anaesthetic needle, we try to ensure that patients do not breathe whenever any needle is, or could be, near the pleura or when the needle is being moved within the lung.

Metastic deposits in the needle track have been reported more frequently after cutting needle biopsy ${ }^{6} 1819$ than after fine needle aspiration. ${ }^{28}$ With a Trucut needle the specimen is sheathed by the outer needle during withdrawal. Despite this we saw two patients develop secondary deposits at the site of needle penetration, and in one man this was the only evidence of recurrent tumour. Some workers ${ }^{19}$ regard a potentially operable carcinoma as a contraindication to cutting needle biopsy. We believe that this advice overstates the case, but certainly the risk of needle track secondaries has to be considered along with the other risks and benefits before a biopsy is advised in such patients. One of our patients with a needle track secondary had an 
adenocarcinoma and the two patients previously reported whose histological details were recorded also had adenocarcinomas.

Screening control of the procedure must increase diagnostic accuracy and decrease complications. Nevertheless, the rate of extensive or severe haemorrhage was significantly higher in patients with lesions more than $8 \mathrm{~cm}$ from the skin surface. Such lesions can nowadays be approached via a fibreoptic bronchoscope with the use of $x$ ray screening and this technique is safer. Others have concluded that maximal penetration of the lung should not exceed $3 \mathrm{~cm}^{11}$ or $4 \mathrm{~cm}^{9}$ beneath the pleura.

We believe that accurate diagnosis of localised lung disease is important and that Trucut needle biopsy conducted in controlled conditions is a valuable component of the range of biopsy techniques now available. We conclude (table 3 ) that Trucut needle biopsy of localised intrathoracic lesions is particularly indicated where the lesion is $2 \mathrm{~cm}$ or greater in maximum diameter and lies $8 \mathrm{~cm}$ or less from the skin surface, because it produces a histological specimen with a higher degree of diagnostic accuracy for both malignant and nonmalignant lesions than do cytological techniques. Lesions less than $2 \mathrm{~cm}$ in diameter are better approached with an aspirating needle or Nordenstrom type of needle. Lesions more than $8 \mathrm{~cm}$ from the intended biopsy site should be approached via a fibreoptic bronchoscope in the first instance.

We are grateful to our colleagues Drs AHC Couch and PF Jenkins, Mr WF Kerr, Dr RA Mulligan, and Mr BA Ross for kindly referring patients; to our radiographers, particularly Miss $\mathrm{J}$ Palmer; and to our secretaries, particularly Mrs J Edwards.

\section{References}

' Leyden H. Uber infectiose Pneumonie. Deutsch Med Wochenschr 1883;9:52-4.

${ }^{2}$ Menetrier P. Cancer primitif du poumon. Bull Soc Anat Paris 1886; 2:643-7.

${ }^{3}$ Sarin LR, Bhatnagar L. Needle biopsy of the lung. Indian J Med Sci 1959;13:901-4.

${ }^{4}$ Miller FL. Percutaneous needle biopsy in clinically inoperable pulmonary tumours. Armed Forces Med J 1960;11:858-71.

s Sabour MS, Osman LM, Le Golvan PC, Ishak KG. Needle biopsy of the lung. Lancet 1960;ii:182-4.

- Aronovitch M, Chartier J, Kahana LM, Meakins JF, Groszman M. Needle biopsy as an aid to the precise diagnosis of intrathoracic disease. Canad Med Ass J 1963;88:120-7.

7 Smith WG. Needle biopsy of the lung. Thorax 1964;19:68-78.

${ }^{8}$ Krumholz RA, Manfredi F, Weg JG. Rosenbaum D. Needle biopsy of the lung. Ann Intern Med 1966; 65:293-307.
9 Adamson JS, Bates JH. Percutaneous needle biopsy of the lung. Arch Intern Med 1967;119:164-9.

10 Youmans CR, deGroot WJ, Marshall R, Morettin LB, Derrick JR. Needle biopsy of the lung in diffuse parenchymal disease. Am J Surg 1970;120:637-43.

1 Zavala DC, Bedell GN. Percutaneous lung biopsy with a cutting needle. Am Rev Respir Dis 1972;106:186-93.

12 Herman PG, Hessel SJ. The diagnostic accuracy and complications of closed lung biopsies. Radiology 1977;125: $11-4$.

${ }^{13}$ Knight RK. How to biopsy the lung and pleura. $B r J$ Hosp Med 1981;26:160-3.

${ }^{14}$ Knight RK. Non-endoscopic biopsy techniques in thoracic medicine. In: Emerson PA, ed. Thoracic medicine. London: Butterworths, 1981: 209.

is Janower ML, Land RE. Lung biopsy. Bronchial brushing and percutaneous puncture. Radiol Clin North Am 1971;9:73-83.

${ }^{16}$ Meyer JE, Ferrucci JT, Janower ML. Fatal complications of percutaneous lung biopsy. Review of the literature and report of a case. Radiology 1970;96:47-8.

17 Norenberg R, Claxton CP, Takaro T. Percutaneous needle biopsy of the lung. Report of two fatal complications. Chest 1974;66:216-8.

18 Dutra FR, Geraci CL. Needle biopsy of the lung. JAMA 1954;155:21-4.

${ }^{19}$ Wolinsky H, Lischner MW. Needle track implantation of tumour after percutaneous lung biopsy. Ann Intern Med 1969;71:359-62.

${ }^{20}$ Lauby VW, Burnett WE, Rosemond GP, Tyson RR. Value and risk of biopsy of pulmonary lesions by needle aspiration. Twenty-one years' experience. $J$ Thorac Cardiovasc Surg 1965;49:159-72.

${ }^{21}$ Walls WJ, Thornbury JR, Naylor B. Pulmonary needle aspiration biopsy in the diagnosis of Pancoast tumours. Radiology 1974;111:99-102.

22 Dick R, Heard BE, Hinson KFW, Kerr IH, Pearson MC Aspiration needle biopsy of thoracic lesions: an assessment of 227 biopsies. $\mathrm{Br} J$ Dis Chest 1974;68:86-94.

${ }^{23}$ Sargent EN, Turner AF, Gordonson J, Schwinn CP, Pashky O. Percutaneous pulmonary needle biopsy. Report of 350 patients. Am J Roentgenol 1974; 122: 758-68.

${ }^{24}$ Grech P, Gray PB, Lambourne CA, Clark RA. Townshend RH. Aspiration needle biopsy for solitary, peripheral lung lesions: a review of 50 examinations. Br J Dis Chest 1978;72:235-41.

${ }^{25}$ Sagel SS, Ferguson TB, Forrest JV, Roper CL, Weldon CS, Clark RE. Percutaneous transthoracic aspiration needle biopsy. Ann Thorac Surg 1978;26:399-405.

${ }^{26}$ Lalli AF, McCormack LJ, Zelch M, Reich NE, Belovich D. Aspiration biopsies of chest lesions. Radiology 1978; 127:35-40.

27 Flower CDR, Verney GI. Percutaneous needle biopsy of thoracic lesions - an evaluation of 300 biopsies. Clin Radiol 1979;30:215-8.

${ }^{28}$ Sinner WN. Pulmonary neoplasms diagnosed with transthoracic needle biopsy. Cancer 1979;43:1533-40.

${ }^{29}$ Berquist TH, Bailey PB, Cortese DA, Miller WE. Transthoracic needle biopsy: accuracy and complications in relation to location and type of lesion. Mayo Clin Proc 1980;55:475-81.

${ }^{30}$ Zavala DC, Schoell JE. Ultrathin needle aspiration of the lung in infectious and malignant disease. $A m R e v$ Respir Dis 1981;123:125-31. 
${ }^{31}$ Allison DJ, Hemingway AP. Percutaneous needle biopsy of the lung. Br Med J 1981;282:875-8.

32 Woolf CR. Applications of aspiration lung biopsy with a review of the literature. Chest 1954;25:283-301.

${ }^{33}$ Westcott JL. Air embolism complicating percutaneous needle biopsy of the lung. Chest $1973 ; 63: 108-10$.

34 Pearce JG. Patt NL. Fatal pulmonary haemorrhage after percutaneous aspiration lung biopsy. Am Rev Respir Dis 1974;110:346-9.

${ }^{35}$ Landman S, Burgener FA, Lim GHK. Comparison of bronchial brushing and percutaneous needle aspiration biopsy in the diagnosis of malignant lung lesions.
Radiology 1975;115:275-8.

36 Payne CR, Stovin PGI, Barker V, McVittie S, Stark JE. Diagnostic accuracy of cytology and biopsy in primary bronchial carcinoma. Thorax 1979;34:294-9.

${ }^{37}$ Rudd RM, Gellert AR, Boldy DAR, et al. Bronchoscopic and percutaneous aspiration biopsy in the diagnosis of bronchial carcinoma cell type. Thorax 1982;37:462-5.

${ }^{38}$ Greene RE. Transthoracic needle aspiration biopsy. In: Athanasoulis CA, Pfister RC, Greene RE, Robertson $\mathrm{GH}$, eds. Intervention radiology. Philadelphia: WB Saunders, 1982:587-634. 